\title{
What motivates gambling behavior? Insight into dopamine's role
}

\author{
Patrick Anselme ${ }^{1 *}$ and Mike J. F. Robinson ${ }^{2,3}$ \\ ${ }^{1}$ Département de Psychologie, Université de Liège, Liège, Belgium \\ ${ }^{2}$ Department of Psychology, University of Michigan, Michigan, MI, USA \\ ${ }^{3}$ Department of Psychology, Wesleyan University, Connecticut, CT, USA \\ *Correspondence: panselme@ulg.ac.be
}

\section{Edited by:}

Bryan F. Singer, University of Michigan, USA

Reviewed by:

Nichole Neugebauer, University of Chicago, USA

Keywords: dopamine, motivation, gambling, loss, reward uncertainty
It is commonly believed that monetary gain is the cause of gambling behavior in humans. Mesolimbic dopamine (DA), the chief neuromediator of incentive motivation, is indeed released to a larger extent in pathological gamblers (PG) than in healthy controls (HC) during gambling episodes (Linnet et al., 2011; Joutsa et al., 2012), as in other forms of compulsive and addictive behavior. However, recent findings indicate that the interaction between DA and reward is not so straightforward (Blum et al., 2012; Linnet et al., 2012). In PG and HC, DA release seems to reflect the unpredictability of reward delivery rather than reward per se. This suggests that the motivation to gamble is strongly (though not entirely) determined by the inability to predict reward occurrence. Here we discuss several views of the role of DA in gambling, and attempt to provide an evolutionary framework to explain its role in uncertainty.

\section{TRADITIONAL VIEW: MONEY DRIVES GAMBLING}

Common sense suggests that if gambling at casinos is attractive for many people, it is because it offers an opportunity to win money (Dow Schüll, 2012). Of course, a "big win" is rare, but the random component behind most games and the publicizing of big winners lets people believe that the chance of winning a lot is not so unlikely. In this traditional view, money is a gambler's primary motivation, and randomness in games allows the gambler to hope that the gains will overcome the losses.

This view is compatible with the evidence that DA released in the nucleus accumbens, a mesolimbic region in the brain, magnifies the attractiveness of rewards and conditioned cues (Berridge, 2007). Mesolimbic DA transforms neutral cues into conditioned cues when they come to reliably predict reward delivery (Melis and Argiolas, 1995; Peciña et al., 2003; Flagel et al., 2011). Money is certainly a strong conditioned cue, which has been associated with abundance and power in all human civilizations. As with other reward sources, money is known to enhance mesolimbic DA levels in the human striatum during gambling episodes, suggesting that money is what motivates gamblers (Koepp et al., 1998; Zald et al., 2004; Zink et al., 2004; Pessiglione et al., 2007). For example, Joutsa et al. (2012) showed that DA is released in the ventral striatum during instances of high- but not low-reward, in both PG and HC, and that the severity of symptoms in PG is associated with larger DA responses.

\section{THE ATTRACTIVENESS OF LOSSES}

Although the traditional view is in agreement with neuroscientific data, it fails to explain why people often describe gambling as a pleasant activity rather than as an opportunity to gain money. During gambling episodes, PG report euphoric feelings comparable to those experienced by drug users (van Holst et al., 2010), and the more PG lose money, the more they tend to persevere in this activitya phenomenon referred to as loss-chasing (Campbell-Meiklejohn et al., 2008). Such results are hardly compatible with the traditional view. Animal and human studies indicate that the role of DA in reward is, at least in gambling, more complex than initially believed (Linnet, 2013).

Determining the exact timing of subjective feelings or how losses spur on a gambler's desire to play during gambling episodes is difficult because different emotions and cognitions constantly overlap. Nevertheless, Linnet et al. (2010) were able to measure mesolimbic DA release in PG and HC winning or losing money. Unexpectedly, they found no difference in dopaminergic responses between PG and $\mathrm{HC}$ who won money. Dopamine release in the ventral striatum, however, was more pronounced for the losses in PG relative to HC. Given the motivational impact of mesolimbic DA, Linnet and colleagues argue that this effect could explain losschasing in PG. In addition, they point out that "PG are not hyperdopaminergic per se, but have increased DA susceptibility toward certain types of decisions and behavior" (p. 331). This finding that DA release is higher in PG losing money than in PG winning money is consistent with the evidence that "near misses" enhance the motivation to gamble and recruit the brain reward circuit more than "big wins" (Kassinove and Schare, 2001; Clark et al., 2009; Chase and Clark, 2010). Possibly related to this phenomenon is the evidence that, compared with gains, the amount of monetary losses has limited effect on the extent to which probabilistic (and delayed) losses are discounted in humans (Estle et al., 2006). This suggests that a lower probability (and a longer delay) reduces a gambler's motivation less when losses rather than gains are involved. In contrast, the big win hypothesis suggests that pathological gambling develops in individuals 
that initially experienced large monetary gains, but the attempts to demonstrate this effect on persistence of gambling have failed (Kassinove and Schare, 2001; Weatherly et al., 2004). Current evidence therefore suggests that losses contribute to motivate gambling more than gains.

\section{THE ATTRACTIVENESS OF REWARD UNCERTAINTY}

One of the main underlying factors to the phenomenon of loss-chasing may relate to the importance of reward uncertainty. Studies have shown that reward uncertainty rather than reward per se, will magnify mesolimbic DA, both in monkeys (Fiorillo et al., 2003; de Lafuente and Romo, 2011) and healthy human participants (Preuschoff et al., 2006). In PG, accumbens DA is maximal during a gambling task when the probability of winning and losing money is identicala $50 \%$ chance for a two-outcome event representing maximal uncertainty (Linnet et al., 2012). Although non-dopaminergic neurons might also be involved in the coding of reward uncertainty (Monosov and Hikosaka, 2013), these results based on electrophysiological and neuroimaging techniques indicate that DA is crucial for the coding of reward uncertainty. This suggestion is corroborated by a large number of behavioral studies, showing that mammals and birds respond more vigorously to conditioned cues predicting uncertain rewards (Collins et al., 1983; Anselme et al., 2013; Robinson et al., under review) and tend to prefer an uncertain food option over a certain food option in dualchoice tasks (Kacelnik and Bateson, 1996; Adriani and Laviola, 2006), sometimes despite a lower reward rate (Forkman, 1991; Gipson et al., 2009). According to Greg Costikyan, an award-winning game designer, games cannot hold our interest in the absence of uncertainty-which can take many forms, occurring in the outcome, the game's path, analytical complexity, perception, and so on (Costikyan, 2013). Discussing the game of Tic-Tac-Toe, Costikyan (p. 10) notes that this game is dull for anyone beyond a certain age because its solution is trivial. The reason why children play this game with enjoyment is that they do not understand that the game has an optimal strategy; for children, the game of Tic-Tac-Toe produces an uncertain outcome. A predictable game is dull, just like a detective novel for which the identity of the murderer is known in advance. Based on this assumption, Zack and Poulos (2009) note that several payoff schedules (slot machines, roulette, and dice game of craps) have a probability of winning close to $50 \%$, so that they are expected to elicit maximal DA release and, therefore, reinforce the act of gambling.

The evidence that uncertainty itself appears to be a source of motivation is visible in the growing trend of pathological gambling that involves extended play at video poker or slot machines (Dow Schüll, 2012). Individuals are playing to play rather than to win, and monetary wins are conceived as the opportunity to extend the duration of play, rather than the game's main objective. In addition, game programmers have uncovered a profitable trend toward larger and larger number of bets per round of a given game (in Australia, $>100$ bets on a given roll), with smaller and smaller amounts (going as low as one cent), giving rise to a "losses disguised as wins" effect, where players win less than they wagered (Dixon et al., 2010). It is almost as if players were drawn to placing bets or trying to uncover the algorithm that determines the wins and losses (this is often reported in players, see Dow Schüll, 2012). Recently, we have shown in adult rats that an initial exposure (8 days) to conditioned cues predicting highly uncertain rewards sensitizes responding to those cues in the long term (for at least 20 days) despite a gradual reduction in the level of uncertainty (Robinson et al., under review). No behavioral sensitization was apparent following a later exposure to high uncertainty (rewards were provided with certainty during the first 8 days). This result is compatible with other findings showing that persistent gambling behavior is more likely to occur in individuals that experience unpredictable environments and gambling situations early in life (Scherrer et al., 2007; Braverman and Shaffer, 2012).

\section{A POSSIBLE EVOLUTIONARY ORIGIN OF GAMBLING BEHAVIOR}

Since wins are rare and often small during gambling episodes, it is unlikely that they are sufficient to motivate people to persevere in the task. The fact that losses can motivate gambling more than gains is also difficult to understand. So, why do people gamble? Pathological gambling is certainly maladaptive behavior, but the attractiveness of uncertain rewards is so widespread in the animal kingdom that this tendency should have an adaptive origin. Here we suggest a hypothesis-referred to as the compensatory hypothesis-developed by one of the authors, that describes gambling-like behavior in an evolutionary framework (Anselme, 2013).

In nature, animals are subject to a lack of cognitive control in many circumstances; they are often unable to predict what is going to happen. This essentially occurs for two reasons. First, the distribution of natural resources is random, so that a large number of responses must be produced before finding vital resources. Second, the reliability of conditioned cues is often imperfect-e.g., for some species, fruit-trees may act as conditioned cues because of their association with reward (the presence of fruits), but this association is unreliable since fruit-trees have no fruits for most of the year. Given this lack of cognitive control about objects and events, it can be argued that if reward uncertainty were not a source of motivation, most behaviors would extinguish because of the high failure rate (and energy loss) experienced by animals. The compensatory hypothesis suggests that, when a significant object or event's predictability is low, motivational processes are recruited to compensate for the inability to make correct predictions; motivation would act as a mechanism to delay extinction (Anselme, 2013). In other words, allowing an animal to persevere in a task is only possible if its behavior is motivated by the lack of predictability (i.e., uncertainty) rather than by reward itself. The compensatory hypothesis could explain why losses are so important in motivating human gamblers: without the opportunity of receiving no reward, gains become predictable and hence most games become dull (Costikyan, 2013). In addition, this hypothesis provides an interpretation to the evidence that, like physiological deprivations (Nader et al., 1997), psychosocial deprivations such as a lack of maternal care enhance mesolimbic DA release and, correlatively, incentive motivation to seek food (Lomanowska 
et al., 2011). Psychosocial deprivations also seem to be a cause of gambling-like behavior in both pigeons and humans (van Holst et al., 2010; Pattison et al., 2013). In fact, all forms of deprivation result from the inability to predict how to find/obtain appropriate stimuliwhether food, social relationships, opportunities to work and play, etc. In most cases, this inability is a consequence of environmental poverty. On account of this, poor environments resemble unpredictable environments and the compensatory hypothesis suggests that, in both cases, a higher motivation is recruited to persevere in the laborious task of finding resources.

Assuming that this interpretation is correct, gambling behavior in humans could be phylogenetically inherited from older mammalian species whose members motivated by reward uncertainty had a better chance of survival in complex, dynamic environments. Pathological gambling might be the exaggeration of a natural tendency exploited by casinos and games of chance. Of course, uncertaintydriven motivation is no longer required to survive within most western cultures. However, gambling might be hijacking an evolutionary system designed to resolve uncertainty by spurring pulses of motivation, despite or because of repeated losses. How could pathological gambling be addressed? We think that this psychopathology should certainly be treated on a case-by-case basis, depending on the vulnerability of each PG. For example, favoring enrichment of a PG's daily environment by varying leisure activities and social relations may reduce his desire to seek a surplus of stimulation. At a societal level, one approach allowing to address pathological gambling might be that gamblers at casinos can win more often than they lose but only very small gains (similar to the wagered amounts) in order to render gambling persistence less attractive. More thorough investigations are needed to identify the parameters underpinning the addictive power of games and to promote the development of games which do not exploit our phylogenetic vulnerability.

\section{REFERENCES}

Adriani, W., and Laviola, G. (2006). Delay aversion but preference for large and rare rewards in two choice tasks: implications for the measurement of self-control parameters. BMC Neurosci. 7:52. doi: 10.1186/1471-2202-7-52

Anselme, P. (2013). Dopamine, motivation, and the evolutionary significance of gambling-like behaviour. Behav. Brain Res. 256C, 1-4. doi: 10.1016/j.bbr.2013.07.039

Anselme, P., Robinson, M. J. F., and Berridge, K. C. (2013). Reward uncertainty enhances incentive salience attribution as sign-tracking. Behav. Brain Res. 238, 53-61. doi: 10.1016/j.bbr.2012. 10.006

Berridge, K. C. (2007). The debate over dopamine's role in reward: the case for incentive salience. Psychopharmacology (Berl) 191, 391-431. doi: 10.1007/s00213-006-0578-x

Blum, K., Gardner, E., Oscar-Berman, M., and Gold, M. (2012). "Liking" and "wanting" linked to reward deficiency syndrome (RDS): hypothesizing differential responsivity in brain reward circuitry. Curr. Pharm. Des. 18, 113. doi: 10.2174/138161212798919110

Braverman, J., and Shaffer, H. J. (2012). How do gamblers start gambling: identifying behavioural markers for high-risk internet gambling. Eur. J. Public Health 22, 273-278. doi: 10.1093/eurpub/ckp232

Campbell-Meiklejohn, D. K., Woolrich, M. W. Passingham, R. E., and Rogers, R. D. (2008). Knowing when to stop: the brain mechanisms of chasing losses. Biol. Psychiatry 63, 293-300. doi: 10.1016/j.biopsych.2007.05.014

Chase, H. W., and Clark, L. (2010). Gambling severity predicts midbrain response to near-miss outcomes. J. Neurosci. 30, 6180-6187. doi: 10.1523/ JNEUROSCI.5758-09.2010

Clark, L., Lawrence, A. J., Astley-Jones, F., and Gray, N. (2009). Gambling near-misses enhance motivation to gamble and recruit win-related brain circuitry. Neuron 61, 481-490. doi: 10.1016/j.neuron.2008. 12.031

Collins, L., Young, D. B., Davies, K., and Pearce, J. M. (1983). The influence of partial reinforcement on serial autoshaping with pigeons. Q. J. Exp. Psychol. B 35, 275-290.

Costikyan, G. (2013). Uncertainty in Games. Cambridge, MA: MIT Press.

de Lafuente, V., and Romo, R. (2011). Dopamine neurons code subjective sensory experience and uncertainty of perceptual decisions. Proc. Natl. Acad. Sci. U.S.A. 108, 19767-19771. doi: 10.1073/pnas.1117 636108

Dixon, M. J., Harrigan, K. A., Sandhu, R., Collins, K., and Fugelsang, J. A. (2010). Losses disguised as wins in modern multi-line video slot machines. Addiction 105, 1819-1824. doi: 10.1111/j.13600443.2010.03050.x

Dow Schüll, N. (2012). Addiction by Design: Machine Gambling in Las Vegas, 1st Edn. Princeton, NJ: Princeton University Press.

Estle, S. J., Green, L., Myerson, J., and Holt, D. D. (2006). Differential effects of amount on temporal and probability discounting of gains and losses. Mem. Cognit. 34, 914-928. doi: 10.3758/ BF03193437

Fiorillo, C. D., Tobler, P. N., and Schultz, W. (2003). Discrete coding of reward probability and uncertainty by dopamine neurons. Science 299, 1898-1902. doi: 10.1126/science. 1077349
Flagel, S. B., Clark, J. J., Robinson, T. E., Mayo, L., Czuj, A., Willuhn, I., et al. (2011). A selective role for dopamine in stimulus-reward learning. Nature 469, 53-57. doi: 10.1038/nature09588

Forkman, B. (1991). Some problems with current patch-choice theory: a study on the Mongolian gerbil. Behaviour 117, 243-254. doi: 10.1163/156853991X00553

Gipson, C. D., Alessandri, J. J. D., Miller, H. C., and Zentall, T. R. (2009). Preference for 50\% reinforcement over $75 \%$ reinforcement by pigeons. Learn. Behav. 37, 289-298. doi: 10.3758/LB.37.4.289

Joutsa, J., Johansson, J., Niemelä, S., Ollikainen, A., Hirvonen, M. M., Piepponen, P., et al. (2012). Mesolimbic dopamine release is linked to symptom severity in pathological gambling. Neuroimage 60, 1992-1999. doi: 10.1016/j.neuroimage.2012.02.006

Kacelnik, A., and Bateson, M. (1996). Risky theories: the effects of variance on foraging decisions. Am. Zool. 36, 402-434.

Kassinove, J. I., and Schare, M. L. (2001). Effects of the "near miss" and the "big win" on persistence at slot machine gambling. Psychol. Addict. Behav. 15, 155-158. doi: 10.1037/0893-164X.15.2.155

Koepp, M. J., Gunn, R. N., Lawrence, A. D., Cunningham, V. J., Dagher, A., Jones, T., et al. (1998). Evidence for striatal dopamine release during a video game. Nature 393, 266-268. doi: $10.1038 / 30498$

Linnet, J. (2013). The Iowa Gambling Task and the three fallacies of dopamine in gambling disorder. Front. Psychol. 4:709. doi: 10.3389/fpsyg.2013.00709

Linnet, J., Møller, A., Peterson, E., Gjedde, A., and Doudet, D. (2011). Dopamine release in ventral striatum during Iowa Gambling Task performance is associated with increased excitement levels in pathological gambling. Addiction 106, 383-390. doi: 10.1111/j.1360-0443.2010.03126.x

Linnet, J., Mouridsen, K., Peterson, E., Møller, A., Doudet, D. J., and Gjedde, A. (2012). Striatal dopamine release codes uncertainty in pathological gambling. Psychiatry Res. 204, 55-60. doi: 10.1016/j.pscychresns.2012.04.012

Linnet, J., Peterson, E., Doudet, D. J., Gjedde, A., and Møller, A. (2010). Dopamine release in ventral striatum of pathological gamblers losing money. Acta Psychiatr. Scand. 122, 326-333. doi: 10.1111/j.1600-0447.2010.01591.x

Lomanowska, A. M., Lovic, V., Rankine, M. J., Mooney, S. J., Robinson, T. E., and Kraemer, G. W. (2011). Inadequate early social experience increases the incentive salience of reward-related cues in adulthood. Behav. Brain Res. 220, 91-99. doi: 10.1016/j.bbr.2011.01.033

Melis, M. R., and Argiolas, A. (1995). Dopamine and sexual behavior. Neurosci. Biobehav. Rev. 19, 19-38. doi: 10.1016/0149-7634(94)00020-2

Monosov, I. E., and Hikosaka, O. (2013). Selective and graded coding of reward uncertainty by neurons in the primate anterodorsal septal region. Nat. Neurosci. 16, 756-762. doi: 10.1038/nn.3398

Nader, K., Bechara, A., and van der Kooy, D. (1997). Neurobiological constraints on behavioral models of motivation. Annu. Rev. Psychol. 48, 85-114. doi: 10.1146/annurev. psych.48.1.85 
Pattison, K. F., Laude, J. R., and Zentall, T. R. (2013). Environmental enrichment affects suboptimal, risky, gambling-like choice by pigeons. Anim. Cogn. 16, 429-434. doi: 10.1007/s10071012-0583-x

Peciña, S., Cagniard, B., Berridge, K. C., Aldridge, J. W., and Zhuang, X. (2003). Hyperdopaminergic mutant mice have higher "wanting" but not "liking" for sweet rewards. J. Neurosci. 23, 9395-9402.

Pessiglione, M., Schmidt, L., Draganski, B., Kalisch, R., Lau, H., Dolan, R. J., et al. (2007). How the brain translates money into force: a neuroimaging study of subliminal motivation. Science 316, 904-906. doi: 10.1126/science.1140459

Preuschoff, K., Bossaerts, P., and Quartz, S. R. (2006). Neural differentiation of expected reward and risk in human subcortical structures. Neuron 51, 381-390. doi: 10.1016/j.neuron.2006.06.024

Scherrer, J. F., Xian, H., Kapp, J. M. K., Waterman, B. Shah, K. R., Volberg, R., et al. (2007). Association between exposure to childhood and lifetime traumatic events and lifetime pathological gambling in a twin cohort. J. Nerv. Ment. Dis. 195, 72-78. doi: 10.1097/01.nmd.0000252384.20382.e9

van Holst, R. J., van den Brink, W., Veltman, D. J., and Goudriaan, A. E. (2010). Why gamblers fail to win: a review of cognitive and neuroimaging findings in pathological gambling. Neurosci. Biobehav. Rev. 34, 87-107. doi: 10.1016/j.neubiorev.2009.07.007

Weatherly, J. N., Sauter, J. M., and King, B. M. (2004). The "big win" and resistance to extinction when gambling. J. Psychol. 138, 495-504. doi: 10.3200/ JRLP.138.6.495-504

Zack, M., and Poulos, C. X. (2009). Parallel roles for dopamine in pathological gambling and psychostimulant addiction. Curr. Drug Abuse Rev. 2, 11-25. doi: 10.2174/1874473710902010011

Zald, D. H., Boileau, I., El-Dearedy, W., Gunn, R., McGlone, F., Dichter, G. S., et al. (2004). Dopamine transmission in the human striatum during monetary reward tasks. J. Neurosci. 24, 4105-4112. doi: 10.1523/JNEUROSCI.464303.2004

Zink, C. F., Pagnoni, G., Martin-Skurski, M. E., Chappelow, J. C., and Berns, G. S. (2004). Human striatal responses to monetary reward depend on saliency. Neuron 42, 509-517. doi: 10.1016/S08966273(04)00183-7

Received: 20 October 2013; accepted: 12 November 2013; published online: 02 December 2013.

Citation: Anselme P and Robinson MJF (2013) What motivates gambling behavior? Insight into dopamine's role. Front. Behav. Neurosci. 7:182. doi: 10.3389/fnbeh. 2013.00182

This article was submitted to the journal Frontiers in Behavioral Neuroscience.

Copyright (c) 2013 Anselme and Robinson. This is an open-access article distributed under the terms of the Creative Commons Attribution License (CC BY). The use, distribution or reproduction in other forums is permitted, provided the original author(s) or licensor are credited and that the original publication in this journal is cited, in accordance with accepted academic practice. No use, distribution or reproduction is permitted which does not comply with these terms. 